Article

\title{
Eudragit S100 Entrapped Liposome for Curcumin Delivery: Anti-Oxidative Effect in Caco-2 Cells
}

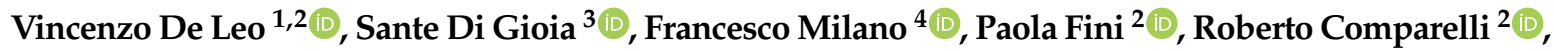 \\ Erminia Mancini ${ }^{5}$, Angela Agostiano ${ }^{1,2}(\mathbb{D})$, Massimo Conese ${ }^{3}$ (D) and Lucia Catucci ${ }^{1,2, *(D)}$ \\ 1 Department of Chemistry, University of Bari, Via Orabona 4, 70126 Bari, Italy; \\ vincenzo.deleo@uniba.it (V.D.L.); angela.agostiano@uniba.it (A.A.) \\ 2 CNR-IPCF Institute for Physical and Chemical Processes, Bari Unit, Via Orabona 4, 70126 Bari, Italy; \\ p.fini@ba.ipcf.cnr.it (P.F.); r.comparelli@ba.ipcf.cnr.it (R.C.) \\ 3 Department of Medical and Surgical Sciences, University of Foggia, Viale L. Pinto 1, 71122 Foggia, Italy; \\ sante.digioia@unifg.it (S.D.G.); massimo.conese@unifg.it (M.C.) \\ 4 CNR-ISPA Institute of Sciences of Food Production, Lecce unit, Via Provinciale Lecce-Monteroni, \\ 73100 Lecce, Italy; francesco.milano@cnr.it \\ 5 CNR-ISPA Institute of Sciences of Food Production, Bari unit, Via G. Amendola 122/O, 70125 Bari, Italy; \\ erminia.mancini@ispa.cnr.it \\ * Correspondence: lucia.catucci@uniba.it; Tel.: +39-080-544-2055
}

Received: 17 December 2019; Accepted: 26 January 2020; Published: 30 January 2020

check for updates

\begin{abstract}
Curcumin is a natural polyphenol with strong antioxidant activity. However, this molecule shows a very poor bioavailability, instability, and rapid metabolism in vivo. In this work curcumin was loaded in Eudragit-coated liposomes to create a gastroresistant carrier, able to protect its load from degradation and free it at the site of absorption in the colon region. Small unilamellar vesicles were prepared and coated with Eudragit by a $\mathrm{pH}$-driven method. The physico-chemical properties of the prepared systems were assessed by light scattering, transmission electron microscopy, infrared spectroscopy, and differential scanning calorimetry. The uptake of vesicles by Caco- 2 cells and the anti-oxidant activity in cells were evaluated. The produced vesicles showed dimensions of about forty nanometers that after covering with Eudragit resulted to have micrometric dimensions at acid $\mathrm{pH}$. The experiments showed that at $\mathrm{pH}>7.0$ the polymeric coating dissolves, releasing the nanometric liposomes and allowing them to enter Caco-2 cells. Delivered curcumin loaded vesicles were then able to decrease significantly ROS levels as induced by $\mathrm{H}_{2} \mathrm{O}_{2}$ in Caco-2 cells. The proposed work showed the possibility of realizing effective gastroresistant curcumin liposome formulations for the delivery of antioxidant molecules to Caco-2 cells, potentially applicable to the treatment of pathological conditions related to intestinal oxidative stress.
\end{abstract}

Keywords: liposomes; Eudragit ${ }^{\circledR}$; curcumin; Caco-2 cells; uptake; anti-oxidant activity

\section{Introduction}

(1E,6E)-1,7-bis (4-hydroxy-3-methoxyphenyl)-1,6-heptadiene-3,5-dione or curcumin is a natural polyphenol isolated from the rhizomes of the plant Curcuma longa L., widely used as a spice, dye, and remedy in oriental folk medicine. Numerous biological activities are recognized to this yellow molecule such as antioxidant, anti-inflammatory, hepatoprotective, wound-healing, anti-proliferative, antibacterial, antifungal and many other properties [1-3]. Although the precise mechanism of action of curcumin are still under investigation by researchers, the innumerable therapeutic benefits deriving from curcumin supplementation are mainly attributable to its antioxidant and anti-inflammatory effects [4]. In addition, this polyphenol and its derivatives showed strong activities against various typologies of cancer by arresting them in various phases of the cell cycle and disease development $[5,6]$. 
Despite the use of curcumin is considered fully safe upon oral administration even at very high doses [1] the therapeutic potentials of curcumin are hindered by several limitations. Indeed curcumin shows: i) A very limited solubility in aqueous environment at neutral and acid $\mathrm{pH}$ (because of strong hydrophobicity of the conjugated alkene chain) [7]; ii) a high instability at alkaline and neutral condition (because of a rapid hydrolytic degradation to various compounds including vanillin, ferulic acid, and feruloyl methane) [8]; and iii) a rapid metabolism and clearance in living organisms (liver was indicated as the major organ responsible for metabolism of curcumin in vivo and glucuronide/sulfate conjugates are the metabolites most present in the general blood circulation) [9].

In order to increase its water solubility or dispersibility, to improve its stability, and ultimately its bioavailability, curcumin has been subjected to numerous technological manipulations aimed at obtaining its micro- or nano-encapsulation in different formulations, complexes, and carriers, as well as its reduction in nanometric crystals with or without stabilizers [1,10-13].

Liposomes are ideal carriers for curcumin delivery in a wide range of applications, as demonstrated by numerous researchers [14-16]. They consist of a phospholipid bilayer, fully biocompatible and safe, that encloses an aqueous core. Therefore, liposomes are capable of simultaneously transporting hydrophobic and hydrophilic molecules as well as amphipathic ones. They can be easily marked both with organic fluorescent molecules and quantum dots with a high quantum yield, emitting in a wide range of wavelengths, ideal for theranostic applications $[17,18]$. In addition, liposomes can carry fully active proteins (including integral membrane proteins), genetic material, and other biomacromolecules [19-21]. Finally, liposomes can be covered with both natural and synthetic polymers that increase their steric and biological stability, adapting them to specific experimental needs [22,23]. In addition, these lipid vesicles can be decorated with molecules able to selectively direct them toward a selected biological target, at tissue, cell, and even sub-cellular level, such as antibodies, aptamers, and other molecular recognition groups.

Unfortunately, uncoated, non-modified liposomes, are susceptible to combined detrimental effects of gastric acid, bile salts, and pancreatic lipases in the gastrointestinal tract, resulting in reduced concentrations of intact liposomes and payload leakage [23]. For this reason, the development of liposomes addressed to oral drug delivery requires particular modifications, at the level of lipid composition and/or at the level of vesicle coating.

In this work, we loaded curcumin in the phospholipid bilayer of small unilamellar vesicles (SUVs, liposomes with diameter less than $80 \mathrm{~nm}$ ) and we realized a gastroresistant polymeric coating around the liposomes through a previously developed procedure [24]. This allowed us to create a carrier, stable at the gastrointestinal level, capable of sequestering the curcumin within the hydrophobic double layer, protecting it from the degradation it would be subjected to in the biological environment, and conveying it inside the intestinal cells. The realized coverage of polymer Eudragit ${ }^{\circledR}$ S 100 proved to be a stable coating at acid and neutral $\mathrm{pH}$ around the vesicles and to dissolve at a slightly alkaline $\mathrm{pH}$, releasing the liposomes in the conditions in which they would be found in vivo in the colon. In vitro tests demonstrated the ability of vesicles to enter in Caco-2 cells through a mechanism of endocytosis. The antioxidant activity in the cells was finally measured.

\section{Materials and Methods}

\subsection{Materials}

All chemicals were purchased at the highest purity available and were used without further purification. Chloroform, ethanol, Sephadex G-50 medium resin, cholesterol, curcumin, the reagent grade salts for the $50 \mathrm{mM} \mathrm{K-phosphate} \mathrm{and} 100 \mathrm{mM} \mathrm{KCl} \mathrm{(pH} \mathrm{7.0)} \mathrm{buffer} \mathrm{solutions,} \mathrm{and} \mathrm{sodium}$ cholate (SC) were purchased from Sigma-Aldrich Italy (Sigma-Aldrich S.r.l., Milan, Italy). Lipoid S100 (LS100, approximately 100\% soybean phosphatidylcholine) was from Lipoid (Lipoid GmbH, Ludwigshafen, Germany). 1-palmitoyl-2-[12-[(7-nitro-2-1,3-benzoxadiazol-4-yl)amino]dodecanoyl]-snglycero-3-phosphocholine (NBD-PC) was from Avanti Polar Lipids (Alabaster, AL, USA). Eudragit 
S100 was a kind gift of Evonik (Evonik Industries AG, Darmstadt, Germany). Sterile filters of cellulose acetate $(0.2 \mu \mathrm{m})$ were from Advantec. All aqueous solutions were prepared by using water obtained from a Milli-Q gradient A-10 system (Millipore, Burlington, MA, USA).

\subsection{Preparation of Liposomes and Eudragit Coated Liposomes (Eu-Liposomes)}

Small unilamellar liposomes (SUVs) were prepared by the micelle-to-vesicle transition (MVT) method as previously described [25]. Briefly, $5 \mathrm{mg}$ of Lipoid S100/cholesterol 5:1 w/w was dissolved in chloroform/methanol and dried with a gentle nitrogen flux to form a thin film on the walls of a conical glass tube. Solvent removal was completed under vacuum conditions ( $24 \mathrm{~h}$ at $1 \mathrm{mbar}$ ). $0.5 \mathrm{~mL}$ of $4 \%$ SC in $50 \mathrm{mM} \mathrm{K-phosphate/100} \mathrm{mM} \mathrm{KCl} \mathrm{buffer} \mathrm{(pH} \mathrm{7.0)} \mathrm{was} \mathrm{added} \mathrm{to} \mathrm{the} \mathrm{lipid} \mathrm{film} \mathrm{and} \mathrm{then} \mathrm{sonicated}$ (20 shots at $20 \mathrm{~W}$ with a Branson Sonicator 250) to form a clear mixed micelle solution. This solution was loaded onto a glass column $20 \mathrm{~cm} \times 1 \mathrm{~cm}$ packed with G-50 Sephadex resin equilibrated with $50 \mathrm{mM} \mathrm{K}$-phosphate/100 mM KCl ( $\mathrm{pH}$ 7.0) for detergent removal by size exclusion chromatography (SEC). Detergent removal from phospholipid/detergent mixed micelles induces vesicle formation. Liposomes were eluted in a $1 \mathrm{~mL}$ fraction after a void volume of about $1.5 \mathrm{~mL}$. The preparation of mixed micelles and the formation of liposomes in the SEC column is very simple and takes place in a few minutes. For curcumin-loaded liposomes, an appropriate amount of antioxidant was added to the lipid blend. Fluorescently labelled liposomes for uptake experiments were prepared by adding to the lipid blend $0.4 \%(\mathrm{w} / \mathrm{w})$ of NBD-PC. Vesicles for cell-based assays were sterilized with $0.2 \mu \mathrm{m}$ sterile filters. Liposomes were encapsulated within Eudragit S100 using a pH-driven method as previously described [24]. Briefly, a $0.25 \%$ solution (w/w) of Eudragit S100 in a 100-mM alkaline phosphate buffer (pH 8.0) was prepared (Alkaline Solution). Total of $1 \mathrm{~mL}$ of liposome suspension and $1 \mathrm{~mL}$ of alkaline solution were mixed for several minutes to form Solution A. Solution A was placed in a syringe and quickly injected into a $0.25 \%(\mathrm{v} / \mathrm{v})$ solution of glacial acetic acid, $\mathrm{pH}=3.0$ (Solution $\mathrm{B}$ ) under sustained magnetic stirring. Solution A and Solution B were mixed in a 1:9 dilution ratio. Eu-liposomes were then harvested by centrifugation and washed with distilled water to remove any excess of reagents.

\subsection{Characterization of Liposomes}

The particle size and polydispersity index (PDI) of liposomes and Eu-liposomes were determined by photon correlation spectroscopy (PCS) using a Zetasizer Nano ZS (Malvern Panalytical Ltd, Malvern, UK). Zeta-potential determination was performed using laser Doppler anemometry (Zetasizer Nano ZS, Malvern Panalytical Ltd, Malvern, UK) after dilution in $\mathrm{KCl}$ solution (1 mM, pH 7.0).

Ultraviolet and visible spectra of solutions and suspensions were acquired by means of a Cary 5000 (Agilent Technologies, Santa Clara, CA, USA) ultraviolet-visible double-beam spectrophotometer. The resolution was set to $1 \mathrm{~nm}$, and Hellma quartz cuvettes of $1 \mathrm{~cm}$ path length and suitable capacity were employed.

Mid-infrared spectra were acquired with a Spectrum One FTIR spectrometer (PerkinElmer, Inc., Waltham, MA, USA) equipped with a deuterated tryglycine sulfate detector. The spectral resolution used for all experiments was $4 \mathrm{~cm}^{-1}$. For ATR measurements, the internal reflection element used was a three-bounce $4 \mathrm{~mm}$-diameter diamond microprism. Sample films were cast directly on the internal reflection element by depositing the solution of interest $(3-5 \mu \mathrm{L})$ onto the upper face of the diamond crystal and letting the solvent to evaporate.

Differential scanning calorimetry (DSC) analyses were performed on a Q200 TA Instruments apparatus (TA Instruments, New Castle, DE, USA). The calorimeter was calibrated using indium as standard metal. A volume of $20 \mu \mathrm{L}$ of liposome samples were placed in aluminum pans. The buffer solution was used as the reference sample. Experiments were carried out using successive heating and cooling scans in the temperature range from 0 to $50^{\circ} \mathrm{C}$ with a heating rate of $2{ }^{\circ} \mathrm{C} / \mathrm{min}$, spaced out by isothermics for $5 \mathrm{~min}$, under $\mathrm{N}_{2}$ gas at a flow rate of $50 \mathrm{~mL} / \mathrm{min}$. In the present study, only heating curves were evaluated and presented. 
The Eu-curc-liposome morphology at different $\mathrm{pH}$ was assessed by transmission electron microscopy (TEM). Micrographs were recorded using a Jeol JEM-1011 microscope (Peabody, MA, USA) working at an accelerating voltage of $100 \mathrm{kV}$ and acquired by an Olympus Quemesa Camera (11 Mpx). Samples were prepared as previously reported [24].

\subsection{Cell Cultures}

All biological experiments were performed by using the human intestinal epithelial cell line Caco-2, obtained from a colon-carcinoma. Cells were grown using high-glucose and L-glutamine Dulbecco's modified Eagle medium (DMEM) medium supplemented with $10 \%$ fetal bovine serum (FBS), $1 \%$ penicillin and streptomycin. The cells were incubated at $37^{\circ} \mathrm{C}$ in a humidified incubator with $5 \% \mathrm{CO}_{2}$ and the culture medium was refreshed every other day.

\subsection{Uptake of Liposome Preparations by Caco-2 Cells}

To evaluate the uptake of liposomes by colon epithelial cells, confluent monolayers of Caco-2 cells were incubated with each of these three different formulation: empty liposomes, curcumin-loaded liposomes (Curc-liposomes), and curcumin-loaded liposomes covered with Eudragit ${ }^{\mathbb{R}}$ (Eu-curc-liposomes) at the final lipid concentration of $1 \mathrm{mg} / \mathrm{mL}$ and final concentration of Curcumin of $2 \mu \mathrm{M}$. All liposomes were labelled with the fluorophore NBD-PC. To determine whether internalization of liposomes was active or passive, cells were either maintained at $37^{\circ} \mathrm{C}$, where energy requiring mechanisms will function normally, or pre-incubated at $4{ }^{\circ} \mathrm{C}$, where all energy requiring mechanisms are inhibited, for $15 \mathrm{~min}$ before nanoparticle exposure. After 2 or $24 \mathrm{~h}$ of incubation with liposomes, cells were treated or not treated with trypan blue ( $0.05 \%$ in phosphate buffered saline (PBS)) to quench extracellular fluorescence. Then cells were detached, resuspended in $50 \mu \mathrm{L}$ PBS and then analyzed by Amnis Flowsight IS100 (Luminex Corporation, Austin, TX, USA). Brightfield scatter plots obtained by plotting area on $\mathrm{x}$-axis vs. aspect ratio on $\mathrm{y}$-axis were generated, then single cells events were gated, and finally 10,000 single-cell events for sample were acquired. The mean fluorescence intensity (MFI; channel 2, $488 \mathrm{~nm}$ excitation laser) was analyzed using Amnis IDEAS software subtracting the values of the negative control. Brightfield and green fluorescent images for any single cell event were collected. The flow cytometer used in this analysis (Amnis FlowSight) combines the statistical power and fluorescence sensitivity of standard flow cytometer with the spatial resolution and quantitative morphology of digital microscopy, as it is based on the capture of images of cells in flow and subsequent pixel-based image analysis of objects. Therefore, merged images from the brightfield illumination channel (channel 1) and the green fluorescence channel were obtained.

\subsection{Anti-Oxidant Activity of Liposome Preparations}

To evaluate the optimal conditions for inducing the oxidative stress, Caco-2 cells were seeded at 30,000/well in a 24-well plate, allowed to reach confluence, and incubated with various $\mathrm{H}_{2} \mathrm{O}_{2}$ concentrations for $24 \mathrm{~h}$. In the experiments aimed at evaluating the anti-oxidant activity of liposomes, Caco-2 cells were incubated for $24 \mathrm{~h}$ with empty liposomes, Cur-liposomes, or Eu-Cur-liposomes. Subsequently medium containing liposomes was removed and cells were treated with $\mathrm{H}_{2} \mathrm{O}_{2}(0.1 \mathrm{mM})$ for $24 \mathrm{~h}$. Reactive oxygen species (ROS) production was evaluated by flow cytometry by using the $2^{\prime}, 7^{\prime}$-dichloro-dihydro-fluorescein diacetate $\left(\mathrm{H}_{2} \mathrm{DCFDA}\right)$ method, as previously described [26]. Cells that were just detached from the plate and not challenged with $\mathrm{H}_{2} \mathrm{O}_{2}$ were used to determine the background levels of fluorescence. Cells were analyzed by the Amnis IDEAS software 6.2 by using the same channels as in the uptake studies.

\subsection{Statistical Analysis}

Statistical analyses were carried out by Prism Version 4, GraphPad Software Inc., La Jolla, CA, USA. Data were expressed as the mean $\pm \mathrm{SD}$. Multiple comparisons were based on one-way analysis of variance (ANOVA) with the Tukey's post hoc test and differences were considered significant when $p<0.05$. 


\section{Results and Discussion}

\subsection{Liposome Preparation and Characterization}

Liposomes and curcumin loaded liposomes (Curc-liposomes) were prepared according to the micelle-to-vesicle transition (MVT) method, obtaining small unilamellar vesicles with dimensions of about $40 \mathrm{~nm}$ (Table 1). The MVT method has therefore allowed to assemble in a simple and fast way liposomes with dimensions in the nanometric range, suitable for the uptake of the vesicles and their payload by Caco-2 cells. Indeed previous studies have shown that liposomes of around $40 \mathrm{~nm}$ give rise to a 12-fold higher uptake in Caco-2 cells than vesicles larger than $100 \mathrm{~nm}$ [27]. Moreover, PDI values of 0.30 were obtained for all vesicles investigated (Table 1). For lipid-based carriers such as liposome developed for drug delivery applications, a PDI of 0.3 and below is considered to be acceptable and indicates a homogenous population of phospholipid vesicles [28]. The incorporation of curcumin at $10 \mu \mathrm{M}$ concentration did not significantly affect the measured mean diameter and PDI values. This amount of curcumin, in fact, was chosen to saturate the lipid bilayer without exceeding its solvent capacity, while guaranteeing an encapsulation yield close to $100 \%$ and an undisturbed vesicle morphology. The zeta potential of these vesicles made of Lipoid S100 (i.e., mainly soy PC) and 20\% (w/w) cholesterol, was around $-7 \mathrm{mV}$, values in line with expectations for this type of vesicles. In order to obtain gastro-resistant vesicles, curcumin-loaded liposomes covered with Eudragit@(Eu-Curc-liposome) were obtained according to a recently described method [24], which allows to obtain clusters of vesicles covered with polymer capable of protecting liposomes and their payload from the acid compartments of the gastrointestinal tract. In acid environment, the obtained Eu-curc-liposomes showed micrometric dimensions with negative zeta potentials, as observed by other authors for methacrylic acid-methyl methacrylate (1:2) copolymer nanoparticles [29]. Before proceeding to cell-based experiments, the Eu-curc-liposomes samples were incubated in PBS at pH 7.5, in order to evaluate the behavior of the polymeric coating at $\mathrm{pH}$ values similar to those in which they would be found in vivo at absorption site. Indeed Eudragit coating, after protecting the liposomes from acidic degradation, should complete its role in large intestine or colon, releasing vesicles at near-neutral $\mathrm{pH}$ [30]. The data in the last row of Table 1 show that at $\mathrm{pH} 7.5$ the sizes of the Eu-curc-liposomes samples return to a nanometric range, indicating the dissolution of the polymeric coating. The zeta potential values are negative and, in absolute value, higher than those measured at acid $\mathrm{pH}$. This evidence suggests that Eudragit residues remain on the surface of the vesicles, and the zeta potential values recorded are to be attributed to the presence of free acrylic acid groups on the vesicle surface [29]. The TEM images obtained (Figure 1) confirmed the Eudragit layer dissolution passing from acid environment (panel B) to pH higher than 7.0 (panel C).

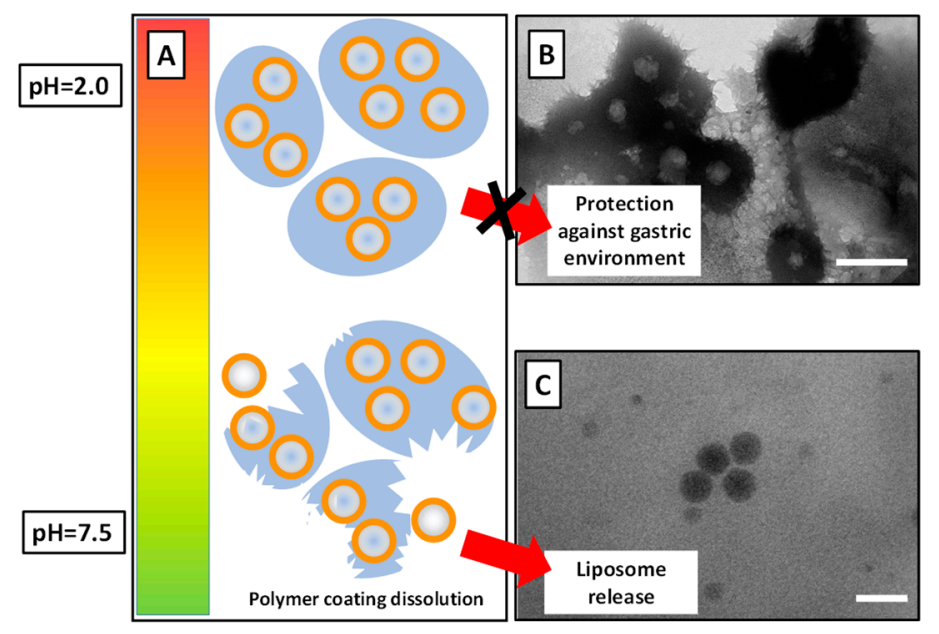

Figure 1. Sketch illustrating the behavior of Eu-curc-liposomes with increasing $\mathrm{pH}$, up to the dissolution of the polymeric coating (A). Transmission electron microscopy (TEM) micrograph of Eu-curc-liposomes at pH 5.0. Scale bar: $200 \mathrm{~nm}$ (B). TEM micrograph of Eu-curc-liposomes at pH 7.5. Scale bar $100 \mathrm{~nm}$ (C). 
Table 1. Encapsulation efficiency (EE), mean size, polydispersity index (PDI) and zeta-potential of liposomes.

\begin{tabular}{|c|c|c|c|c|c|c|}
\hline Sample & $\begin{array}{c}\text { Curcumin } \\
(\mu \mathrm{M})\end{array}$ & EE $(\%)$ & $\mathrm{pH}$ & $\begin{array}{c}\text { Mean Diameter } \\
\text { (nm) }\end{array}$ & PDI & $\begin{array}{c}\text { Zeta-Potential } \\
(\mathrm{mV})\end{array}$ \\
\hline Empty liposomes & 0 & - & 7.0 & $38 \pm 8$ & $0.35 \pm 0.05$ & $-7.4 \pm 0.2$ \\
\hline Curc-liposomes & 10 & $97 \pm 3$ & 7.0 & $37 \pm 7$ & $0.30 \pm .0 .02$ & $-6.8 \pm 0.4$ \\
\hline Eu-Curc-liposome & 10 & $98 \pm 4$ & 5.0 & 1017 * & $1 *$ & $-4.6^{*}$ \\
\hline Eu-Curc-liposome & 10 & $98 \pm 4$ & 7.5 & $45 \pm 8$ & $0.35 \pm 0.05$ & $-16.0 \pm 3.0$ \\
\hline
\end{tabular}

FTIR spectra of Eudragit-coated liposomes and pure liposome were acquired in ATR mode and are shown in Figure 2. The characteristic peaks of Eudragit were at $2953.9 \mathrm{~cm}^{-1}$ because of the presence of $\mathrm{O}-\mathrm{H}$ (carboxylic acid), at $1731 \mathrm{~cm}^{-1}$ because of the $\mathrm{C}=\mathrm{O}$ ester stretching, at $1450.7 \mathrm{~cm}^{-1}$ because of $-\mathrm{CH}_{3}$ bend, while the $\mathrm{C}-\mathrm{O}$ ester signal falls at $1153 \mathrm{~cm}^{-1}$ in accordance with the literature [31]. The liposome spectrum is obviously characterized by lipid signals, including the peak at $1740 \mathrm{~cm}^{-1}$ because of the $\mathrm{C}=\mathrm{O}$ ester stretching and at $1066 \mathrm{~cm}^{-1}$ because of the $\mathrm{C}-\mathrm{O}$ ester stretching. Eu-liposomes show the $\mathrm{C}-\mathrm{O}$ peaks at both the characteristic wavenumbers of the polymer and lipids demonstrating the effective liposome covering. Although in Eu-liposomes the polymer and lipids are organized in separate domains with the Eudragit that externally surrounds the construct, it is reasonable to expect to find both signals in this type of spectra. Indeed in ATR measurement the penetration depth of the evanescent wave in the range $1750 \mathrm{~cm}^{-1}-1000 \mathrm{~cm}^{-1}$ is approximately between $0.9 \mu \mathrm{m}$ and $1.6 \mu \mathrm{m}$, as previously reported [32], therefore much greater than the thickness of the polymer in the Eu-liposomes as indicated by TEM investigations.

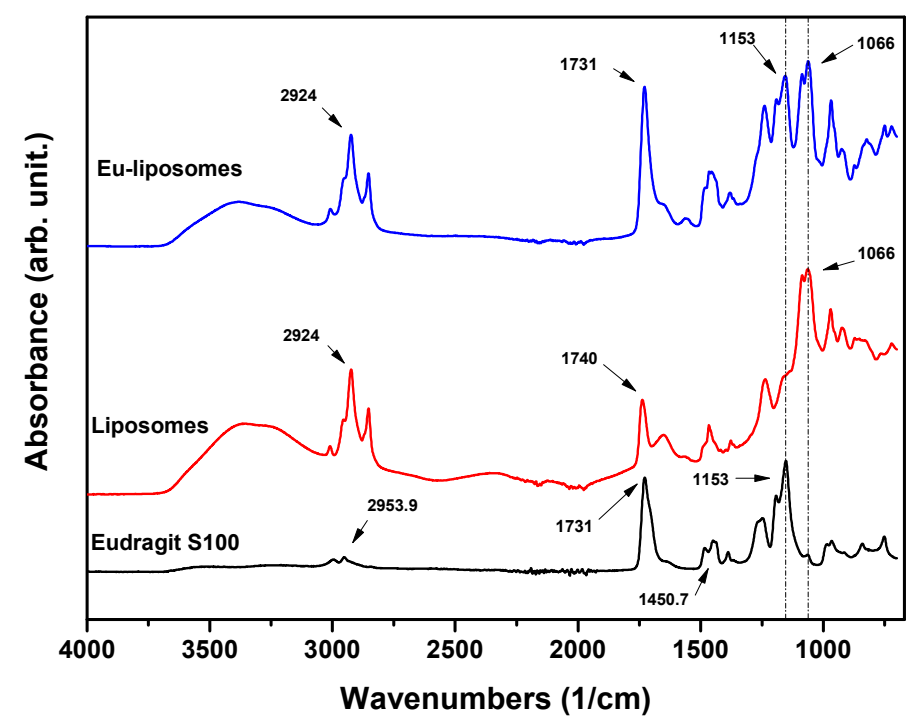

Figure 2. FTIR spectra of Eudragit S100 polymer (black line), liposomes (red line) and Eudragit coated liposomes (blue line).

DSC was used to study the thermotropic properties of empty liposomes, Curc-liposomes and Eu-Curc-liposome (Figure 3). In drug delivery applications the knowledge of information such as the phase transition temperature of vesicles is a decisive factor since it is associated to liposome fluidity and hence to drug permeability. The thermogram obtained by heating empty liposomes (Figure 3, black curve) exhibits a sharp endothermic peak associated to the melting transition from the $\mathrm{L}_{\beta}$ gel phase to the $\mathrm{L}_{\alpha}$ liquid crystalline phase centered at $T \mathrm{~m}=35.2{ }^{\circ} \mathrm{C}$ with a $\Delta T_{1 / 2}$ delta $3.35^{\circ} \mathrm{C}$. At lower temperature, no thermal effects due to other transformation such as pretransitions are evident. 
When liposomes are loaded with curcumin (Figure 3, red curve) the melting transition broadens and shifts to a lower temperature: $\mathrm{Tm}=32.1^{\circ} \mathrm{C}$ with a $\Delta \mathrm{T}_{1 / 2}$ delta of $14.2^{\circ} \mathrm{C}$. The changes of these thermotropic sentitive indicators of physical phenomena that occur in the system, suggest that curcumin induces structural changes in liposomes. In particular, the broadened calorimetric profile indicates a decrease of the cooperativity of the transition which is inversely proportional to the width at the half of the maximum height of the peak [33]. The shift of the melting temperature toward lower temperature means that the presence of curcumin facilitates the trans-gauce conformation transition of lipid hydrocarbon chains increasing the phospholipid rotational freedom [34]. All these curcumin induced changes are likely due to curcumin molecule intercalation between the phospholipids and to its molecular interaction with them as already reported in literature [35]. This modifies the overall balance of the interactions between the head groups and the phospholipid acyl chains that assure the packing of the pure lipid matrix and causes a partial disruption of its packing [36]. In addition, the uploading of curcumin in liposomes gives rise to the formation of regions that differ from each other in terms of interactions and consequently do not melt at the same temperature [33]. DSC profile of Eu-Curc-liposome (Figure 3, blue curve) does not show any thermal transition in the investigated temperature range, confirming the already observed interaction between the polymer and liposomes [24]. A further investigation of these systems (data not shown) indicates that this $\mathrm{pH}$-responsive polymer stabilizes curcumin loaded liposomes until $100^{\circ} \mathrm{C}$.

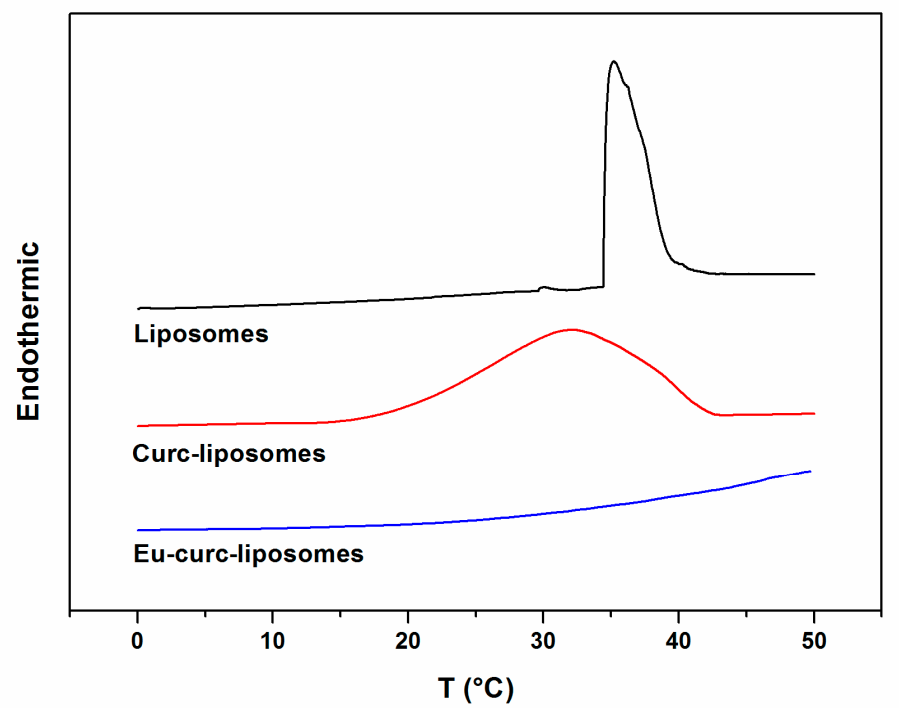

Figure 3. Differential scanning calorimetry (DSC) thermograms of liposomes, Curc-liposomes, and Eu-curc-liposomes.

\subsection{Uptake of Liposomes}

MTT test showed that liposomes, Eu-liposomes, and Eu-curc-liposomes at the final lipid concentration of $1 \mathrm{mg} / \mathrm{mL}$ and final Curcumin concentration of $2 \mu \mathrm{M}$ are not cytotoxic for Caco-2 human colon cell line (data not shown). Liposomes were then evaluated for their uptake by Caco-2 cells, an in-vitro model used for drug uptake and transportation through the intestinal mucosa [37,38]. To assess the effect of short-time incubation at low temperature, Caco-2 cells were first incubated at $4{ }^{\circ} \mathrm{C}$ for $15 \mathrm{~min}$, added with liposomes and then incubated at $37^{\circ} \mathrm{C}$ for either 2 or $24 \mathrm{~h}$. Other cells were incubated for all the experiment execution at $37^{\circ} \mathrm{C}$. In order to evaluate cell-association or uptake, at the end of the incubation period cells were analyzed as such or after treatment with trypan blue (TB), that quenches the extracellular fluorescence. As can be seen in Figure 4, both cell-associated and internalized liposomes increased at $24 \mathrm{~h}$ as compared to $2 \mathrm{~h}$ at $37^{\circ} \mathrm{C}$. The increase for cell-associated liposomes was 1.87 fold for empty liposomes, 2.26 fold for Curc-liposomes, and 3.31 fold for Eu-Curc-liposomes for internalized liposomes, the increase was 2.03-fold for empty liposomes, 2.41-fold for Curc-liposomes, 
and 1.86-fold for Eu-Curc-liposomes. At all conditions, the lack of difference between the mean fluorescence intensity (MFI) values obtained in the absence or presence of TB treatment show that all the cell-associated fluorescence was internalized. Figure $4 \mathrm{~d}$ shows representative condition of cells at $37^{\circ} \mathrm{C}$ for $24 \mathrm{~h}$ after treatment with TB. In general, the pre-incubation at $4{ }^{\circ} \mathrm{C}$ did not substantially change these outcomes, indicating that a short-incubation time at low temperature does not interfere with the subsequent liposomal uptake.

(a)

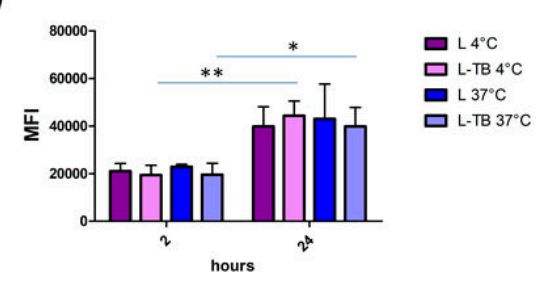

(b)

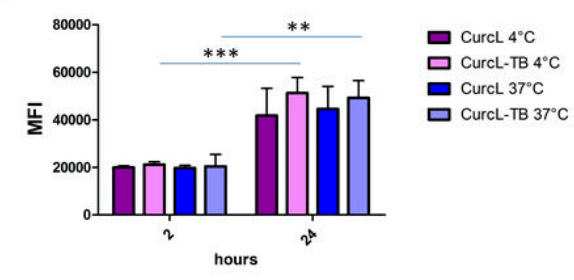

(c)

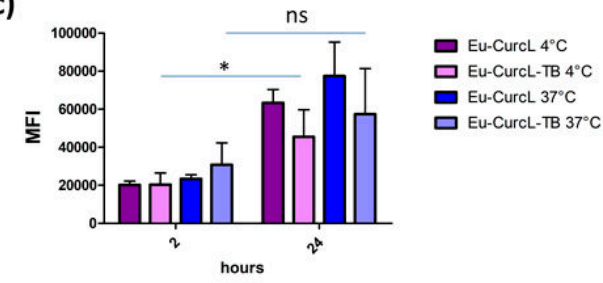

(d)

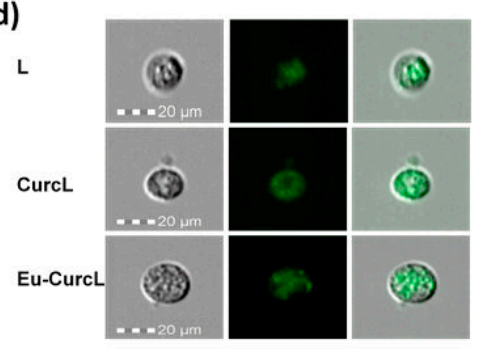

Figure 4. Uptake of empty liposomes (a), Curc-liposomes (b), Eu-Curc-liposomes (c) by Caco-2 cells. Caco-2 cells were incubated with NBD-PC-labelled liposomes either at $4{ }^{\circ} \mathrm{C}$ for $15 \mathrm{~min}$ and then at $37^{\circ} \mathrm{C}$ or at $37^{\circ} \mathrm{C}$ for all the experiment duration. At the end of each incubation time (either $2 \mathrm{~h}$ or $24 \mathrm{~h}$ ), cells were either analyzed as such (cell-associated liposomes) or after TB treatment (internalized liposomes). Data are shown as the mean \pm SD of four replicates for each condition. ${ }^{*} p<0.05$; ${ }^{* *} p<0.01$; *** $p<0.001$. ns: not significant. (d) The cells exemplificative of the condition at $37^{\circ} \mathrm{C}$ for $24 \mathrm{~h}$ with TB are shown as brightfield images (left column), fluorescence channel (middle column), and merge (right column).

Uptake of liposomes by Caco-2 cells has been previously shown to occur in $2 \mathrm{~h}$ at $37^{\circ} \mathrm{C}$ [39], as proved by cytofluorimetric analysis as in our study. We extended this incubation period showing that a prolonged interaction brought to a higher rate of internalized liposomes at $24 \mathrm{~h}$, which will rise curcumin load of intestinal cells. Further experiments are required to explore the energy-dependent uptake of liposomes as well as the endocytic mechanism responsible for it [39].

\subsection{Anti-Oxidant Activity of Liposomes}

In order to evaluate the anti-oxidant activity of liposomes in study, we set-up the conditions to assess the oxidative stress with Caco-2 cells. Hydrogen peroxide was used as oxidative stress-inducing agent. When Caco-2 cells were incubated with various concentrations of $\mathrm{H}_{2} \mathrm{O}_{2}$, a higher amount of fluorescence associated with ROS was observed in the range 0.1-0.5 mM (Figure 5a). As judged by the percentage of positive cells recovered at the end of the assay (Figure $5 b$ ), concentrations higher than $0.5 \mathrm{mM}$ were toxic to the cells. These results are compatible with those obtained by Piccolomini et al. who established in Caco- 2 cells that $\mathrm{H}_{2} \mathrm{O}_{2}$ concentrations higher than $0.5 \mathrm{mM}$ reduced dramatically the cell viability [40]. Based on our and previous results, the $0.1 \mathrm{mM} \mathrm{H}_{2} \mathrm{O}_{2}$ dose was used in subsequent experiments as it was not associated with decreased cell viability as opposed to the higher $\mathrm{H}_{2} \mathrm{O}_{2}$ concentrations.

The anti-oxidant activity was studied after pre-incubation of Caco-2 cells with the different liposomal preparations for $24 \mathrm{~h}$ and then stimulated with $\mathrm{H}_{2} \mathrm{O}_{2}$ for further $24 \mathrm{~h}$. Interestingly, only 
Cur-liposomes and Eu-Cur-liposomes were able to decrease significantly the ROS levels as induced by $\mathrm{H}_{2} \mathrm{O}_{2}$ (Figure $5 \mathrm{c}$ ). Figure $5 \mathrm{~d}$ shows representative cells of each experimental condition.

(a)

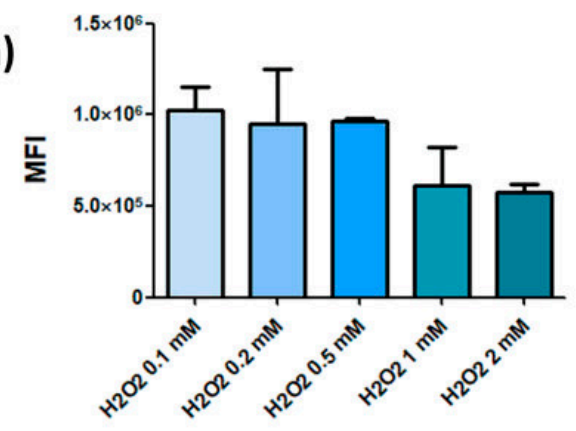

(c)

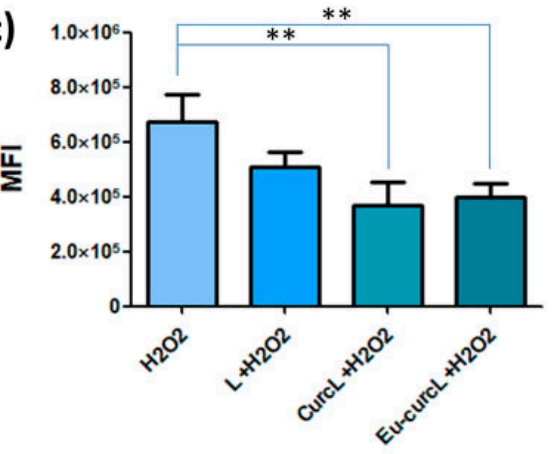

(b)

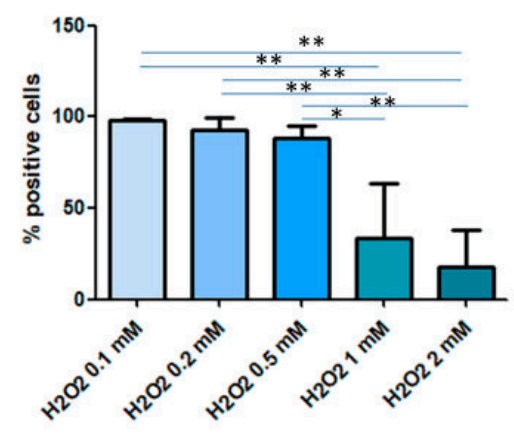

(d)

$\mathrm{H} 2 \mathrm{O} 2$

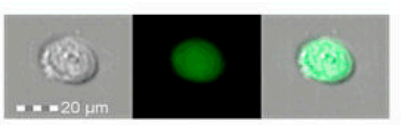

$\mathrm{L}+\mathrm{H} 202$

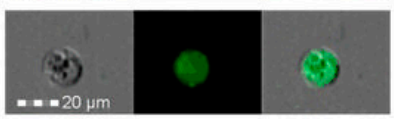

CurcL+H2O2

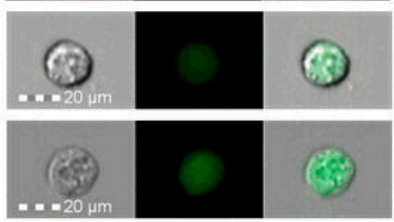

Figure 5. Mean fluorescence intensity (MFI) (a) and \% positive cells (b) associated with oxidative stress as induced by $\mathrm{H}_{2} \mathrm{O}_{2}$. Panel (c) represents the anti-oxidative effect of liposomes on the reactive oxygen species (ROS) levels induced by $0.1 \mathrm{mM} \mathrm{H}_{2} \mathrm{O}_{2}$. Data are shown as the mean $\pm \mathrm{SD}$ of four replicates for each condition. ${ }^{*} p<0.05$;* $p<0.01$. (d) The cells exemplificative of each experimental condition shown in (c) are shown as brightfield images (left column), fluorescence channel (middle column) and merge (right column).

The free radical scavenging activity of curcumin is mainly correlated to the phenolic $\mathrm{OH}$ group and also to the $\mathrm{CH}_{2}$ group of the $\beta$-diketone moiety [41]. We have previously demonstrated in an in-vitro acellular assay that the antioxidant capacity of curcumin-loaded liposomes was very close to that of free curcumin in ethanol [24]. This outcome seems compatible with simulations conducted on model lipid bilayers, which found curcumin stay just below the surface of the lipid bilayer with parallel orientation, close to the interface of lipid head and lipid tail [42]. This particular orientation of the molecule could make curcumin active moieties accessible to free radicals even when embedded into liposomes. On the contrary as prepared Eu-curc-liposomes did not show any appreciable activity, thus confirming a good polymeric coverage of vesicles, while there was a complete recovery of antioxidant activity recorded for the same sample after Eudragit S100 dissolution at $\mathrm{pH}>7.0$ [24]. We also observed that empty (curcumin-free) liposomes exhibited only a very weak activity attributable to phosphatidylcholine lipid (Lipoid S100) used for the assembly of vesicles and which has been demonstrated to act as an oxidative stabilizer in emulsions [43]. In the present study, we confirm these observations in a cellular system, showing that prepared systems can effectively reach the intracellular environment giving rise to a significative antioxidant activity of curcumin. Previous studies conducted on Caco-2 cells have suggested that curcumin incorporated inside the phospholipid bilayer of the liposome is stabilized against the intracellular environment and once vesicles enter the cells by endocytosis it may act longer than free curcumin [44]. In addition, it has been proven that curcumin exerts its antioxidant activity in cells both directly by scavenging ROS and indirectly by increasing the activity of antioxidant enzymes, thus potentially promoting cell survival [45]. 


\section{Conclusions}

Liposomal system suitable for colonic delivery of poor bioavailable and very instable molecules such as curcumin require appropriate surface treatments capable of ensuring stability against the unfavorable conditions of the gastrointestinal tract. The performed experiments showed that in this work a covering of a gastroresistant polymer was effectively realized around the curcumin loaded liposomes. Raising the $\mathrm{pH}$ to near neutral values was able to induce the dissolution of the polymeric coating and to trigger the release of the vesicles. In this form, curcumin loaded liposomes have proved capable of entering Caco-2 cells, where curcumin carried out its antioxidant activity.

Therefore, the proposed approach could provide new insights into the design and optimization of liposome-based delivery systems for the treatment of pathological conditions related to intestinal oxidative stress.

Author Contributions: Conceptualization, V.D.L. and L.C.; methodology, V.D.L., L.C., S.D.G. and M.C.; investigation, V.D.L., S.D.G., P.F., R.C., F.M., E.M.; data curation, V.D.L., S.D.G., F.M.; writing-original draft preparation, V.D.L.; writing-review and editing, V.D.L., F.M., A.A., M.C., and L.C. All authors have read and agreed to the published version of the manuscript.

Funding: This research was funded by Regione Puglia, POR Puglia-FESR-FSE 2014-2020 “Innonetwork” HOQ3PM3 (MOSAICOS).

Acknowledgments: The authors thank Evonik Industries AG for providing the polymer Eudragit S100.

Conflicts of Interest: The authors declare no conflict of interest.

\section{References}

1. Rachmawati, H.; Shaal, L.A.; Müller, R.H.; Keck, C.M. Development of curcumin nanocrystal: Physical aspects. J. Pharm. Sci. 2013, 102, 204-214. [CrossRef] [PubMed]

2. Moghadamtousi, S.Z.; Kadir, H.A.; Hassandarvish, P.; Tajik, H.; Abubakar, S.; Zandi, K. A review on antibacterial, antiviral, and antifungal activity of curcumin. Biomed Res. Int. 2014, 2014, 186864. [PubMed]

3. Menon, V.P.; Sudheer, A.R. Antioxidant and anti-inflammatory properties of curcumin. In The Molecular Targets and Therapeutic Uses of Curcumin in Health and Disease; Aggarwal, B.B., Surh, Y.-J., Shishodia, S., Eds.; Springer US: Boston, MA, USA, 2007.

4. Hewlings, J.S.; Kalman, S.D. Curcumin: A review of its' effects on human health. Foods 2017, 6, 92. [CrossRef]

5. Chen, C.; Sun, W.; Wang, X.; Wang, Y.; Wang, P. Rational design of curcumin loaded multifunctional mesoporous silica nanoparticles to enhance the cytotoxicity for targeted and controlled drug release. Mater. Sci. Eng. C 2018, 85, 88-96. [CrossRef] [PubMed]

6. Tomeh, M.A.; Hadianamrei, R.; Zhao, X. A review of curcumin and its derivatives as anticancer agents. Int. J. Mol. Sci. 2019, 20, 1033. [CrossRef] [PubMed]

7. Jagannathan, R.; Abraham, P.M.; Poddar, P. Temperature-Dependent spectroscopic evidences of curcumin in aqueous medium: A mechanistic study of its solubility and stability. J. Phys. Chem. B 2012, 116, 14533-14540. [CrossRef] [PubMed]

8. Wang, Y.-J.; Pan, M.-H.; Cheng, A.-L.; Lin, L.-I.; Ho, Y.-S.; Hsieh, C.-Y.; Lin, J.-K. Stability of curcumin in buffer solutions and characterization of its degradation products. J. Pharm. Biomed. Anal. 1997, 15, 1867-1876. [CrossRef]

9. Anand, P.; Kunnumakkara, A.B.; Newman, R.A.; Aggarwal, B.B. Bioavailability of curcumin: Problems and promises. Mol. Pharm. 2007, 4, 807-818. [CrossRef]

10. Her, C.; Venier-Julienne, M.-C.; Emilie, R. Improvement of curcumin bioavailability for medical applications. Med. Aromat. Plants (Los Angeles) 2018, 7, 1000326.

11. Jamwal, R. Bioavailable curcumin formulations: A review of pharmacokinetic studies in healthy volunteers. J. Integr. Med. 2018, 16, 367-374. [CrossRef]

12. Gera, M.; Sharma, N.; Ghosh, M.; Huynh, D.L.; Lee, S.J.; Min, T.; Kwon, T.; Jeong, D.K. Nanoformulations of curcumin: An emerging paradigm for improved remedial application. Oncotarget 2017, 8, 66680-66698. [CrossRef] [PubMed] 
13. Zhang, Q.; Polyakov, N.E.; Chistyachenko, Y.S.; Khvostov, M.V.; Frolova, T.S.; Tolstikova, T.G.; Dushkin, A.V.; $\mathrm{Su}, \mathrm{W}$. Preparation of curcumin self-micelle solid dispersion with enhanced bioavailability and cytotoxic activity by mechanochemistry. Drug. Deliv. 2018, 25, 198-209. [CrossRef] [PubMed]

14. Feng, T.; Wei, Y.; Lee, R.J.; Zhao, L. Liposomal curcumin and its application in cancer. Int. J. Nanomed. 2017, 12, 6027-6044. [CrossRef] [PubMed]

15. Cheng, C.; Peng, S.; Li, Z.; Zou, L.; Liu, W.; Liu, C. Improved bioavailability of curcumin in liposomes prepared using a pH-driven, organic solvent-free, easily scalable process. RSC Adv. 2017, 7, 25978-25986. [CrossRef]

16. Sarkar, N.; Bose, S. Liposome-Encapsulated Curcumin-Loaded 3D Printed Scaffold for Bone Tissue Engineering. ACS Appl. Mater. Interfaces 2019, 11, 17184-17192. [CrossRef] [PubMed]

17. De Leo, V.; Catucci, L.; Falqui, A.; Marotta, R.; Striccoli, M.; Agostiano, A.; Comparelli, R.; Milano, F. Hybrid assemblies of fluorescent nanocrystals and membrane proteins in liposomes. Langmuir 2014, 30, 1599-1608. [CrossRef]

18. Depalo, N.; De Leo, V.; Corricelli, M.; Gristina, R.; Valente, G.; Casamassima, E.; Comparelli, R.; Laquintana, V.; Denora, N.; Fanizza, E.; et al. Lipid-based systems loaded with PbS nanocrystals: Near infrared emitting trackable nanovectors. J. Mater. Chem. B 2017, 5, 1471-1481. [CrossRef]

19. De Leo, V.; Catucci, L.; Di Mauro, A.E.; Agostiano, A.; Giotta, L.; Trotta, M.; Milano, F. Effect of ultrasound on the function and structure of a membrane protein: The case study of photosynthetic Reaction Center from Rhodobacter sphaeroides. Ultrason. Sonochem. 2017, 35, 103-111. [CrossRef]

20. De Matos, M.B.C.; Miranda, B.S.; Rizky Nuari, Y.; Storm, G.; Leneweit, G.; Schiffelers, R.M.; Kok, R.J. Liposomes with asymmetric bilayers produced from inverse emulsions for nucleic acid delivery. J. Drug Target. 2019, 27, 681-689. [CrossRef]

21. Smirnova, I.A.; Ädelroth, P.; Brzezinski, P. Extraction and liposome reconstitution of membrane proteins with their native lipids without the use of detergents. Sci. Rep. 2018, 8, 14950. [CrossRef]

22. De Leo, V.; Ruscigno, S.; Trapani, A.; Di Gioia, S.; Milano, F.; Mandracchia, D.; Comparelli, R.; Castellani, S.; Agostiano, A.; Trapani, G.; et al. Preparation of drug-loaded small unilamellar liposomes and evaluation of their potential for the treatment of chronic respiratory diseases. Int. J. Pharm. 2018, 545, 378-388. [CrossRef] [PubMed]

23. He, H.; Lu, Y.; Qi, J.; Zhu, Q.; Chen, Z.; Wu, W. Adapting liposomes for oral drug delivery. Acta Pharm. Sin. B 2019, 9, 36-48. [CrossRef]

24. De Leo, V.; Milano, F.; Mancini, E.; Comparelli, R.; Giotta, L.; Nacci, A.; Longobardi, F.; Garbetta, A.; Agostiano, A.; Catucci, L. Encapsulation of curcumin-loaded liposomes for colonic drug delivery in a $\mathrm{pH}$-responsive polymer cluster using a pH-driven and organic solvent-free process. Molecules 2018, $23,739$. [CrossRef] [PubMed]

25. Mastrogiacomo, D.; Lenucci, M.S.; Bonfrate, V.; Di Carolo, M.; Piro, G.; Valli, L.; Rescio, L.; Milano, F.; Comparelli, R.; De Leo, V.; et al. Lipid/detergent mixed micelles as a tool for transferring antioxidant power from hydrophobic natural extracts into bio-deliverable liposome carriers: The case of lycopene rich oleoresins. RSC Adv. 2015, 5, 3081-3093. [CrossRef]

26. Castellani, S.; Trapani, A.; Spagnoletta, A.; di Toma, L.; Magrone, T.; Di Gioia, S.; Mandracchia, D.; Trapani, G.; Jirillo, E.; Conese, M. Nanoparticle delivery of grape seed-derived proanthocyanidins to airway epithelial cells dampens oxidative stress and inflammation. J. Transl. Med. 2018, 16, 140. [CrossRef] [PubMed]

27. Andar, A.U.; Hood, R.R.; Vreeland, W.N.; DeVoe, D.L.; Swaan, P.W. Microfluidic preparation of liposomes to determine particle size influence on cellular uptake mechanisms. Pharm. Res. 2014, 31, 401-413. [CrossRef]

28. Danaei, M.; Dehghankhold, M.; Ataei, S.; Hasanzadeh Davarani, F.; Javanmard, R.; Dokhani, A.; Khorasani, S.; Mozafari, M.R. Impact of particle size and polydispersity index on the clinical applications of lipidic nanocarrier systems. Pharmaceutics 2018, 10, 57. [CrossRef]

29. Subudhi, B.M.; Jain, A.; Jain, A.; Hurkat, P.; Shilpi, S.; Gulbake, A.; Jain, K.S. Eudragit S100 coated citrus pectin nanoparticles for colon targeting of 5-fluorouracil. Materials 2015, 8, 832-849. [CrossRef]

30. Jain, D.; Panda, A.K.; Majumdar, D.K. Eudragit S100 entrapped insulin microspheres for oral delivery. AAPS PharmSciTech 2005, 6, E100-E107. [CrossRef]

31. Mehta, R.; Chawla, A.; Sharma, P.; Pawar, P. Formulation and in vitro evaluation of Eudragit S-100 coated naproxen matrix tablets for colon-targeted drug delivery system. J. Adv. Technol. Res. 2013, 4, 31-41. 
32. Giotta, L.; Mastrogiacomo, D.; Italiano, F.; Milano, F.; Agostiano, A.; Nagy, K.; Valli, L.; Trotta, M. Reversible binding of metal ions onto bacterial layers revealed by protonation-induced ATR-FTIR difference spectroscopy. Langmuir 2011, 27, 3762-3773. [CrossRef] [PubMed]

33. Yonar, D.; Sünnetçioğlu, M.M. Spectroscopic and calorimetric studies on trazodone hydrochloride-phosphatidylcholine liposome interactions in the presence and absence of cholesterol. Biochim. Biophys. Acta Biomembr. 2014, 1838, 2369-2379. [CrossRef] [PubMed]

34. Zhao, L.; Feng, S.-S.; Kocherginsky, N.; Kostetski, I. DSC and EPR investigations on effects of cholesterol component on molecular interactions between paclitaxel and phospholipid within lipid bilayer membrane. Int. J. Pharm. 2007, 338, 258-266. [CrossRef] [PubMed]

35. Zhang, S.; Wang, X. Effect of vesicle-to-micelle transition on the interactions of phospholipid/sodium cholate mixed systems with curcumin in aqueous solution. J. Phys. Chem. B 2016, 120, 7392-7400. [CrossRef] [PubMed]

36. How, C.W.; Teruel, J.A.; Ortiz, A.; Montenegro, M.F.; Rodríguez-López, J.N.; Aranda, F.J. Effects of a synthetic antitumoral catechin and its tyrosinase-processed product on the structural properties of phosphatidylcholine membranes. Biochim. Biophys. Acta Biomembr. 2014, 1838, 1215-1224. [CrossRef] [PubMed]

37. Beck, R.C.R.; Pohlmann, A.R.; Hoffmeister, C.; Gallas, M.R.; Collnot, E.; Schaefer, U.F.; Guterres, S.S.; Lehr, C.M. Dexamethasone-loaded nanoparticle-coated microparticles: Correlation between in vitro drug release and drug transport across Caco-2 cell monolayers. Eur. J. Pharm. Biopharm. 2007, 67, 18-30. [CrossRef]

38. Jung, I.-W.; Han, H.-K. Effective mucoadhesive liposomal delivery system for risedronate: Preparation and in vitro/in vivo characterization. Int. J. Nanomed. 2014, 9, 2299-2306.

39. Li, X.; Chen, D.; Le, C.; Zhu, C.; Gan, Y.; Hovgaard, L.; Yang, M. Novel mucus-penetrating liposomes as a potential oral drug delivery system: Preparation, in vitro characterization, and enhanced cellular uptake. Int. J. Nanomed. 2011, 6, 3151-3162.

40. Piccolomini, A.F.; Iskandar, M.M.; Lands, L.C.; Kubow, S. High hydrostatic pressure pre-treatment of whey proteins enhances whey protein hydrolysate inhibition of oxidative stress and IL-8 secretion in intestinal epithelial cells. J. Food Nutr. Res. 2012, 56, 17549. [CrossRef]

41. Nimse, S.B.; Pal, D. Free radicals, natural antioxidants, and their reaction mechanisms. RSC Adv. 2015, 5, 27986-28006. [CrossRef]

42. Lyu, Y.; Xiang, N.; Mondal, J.; Zhu, X.; Narsimhan, G. Characterization of interactions between curcumin and different types of lipid bilayers by molecular dynamics simulation. J. Phys. Chem. B 2018, 122, 2341-2354. [CrossRef] [PubMed]

43. Pan, Y.; Tikekar, R.V.; Nitin, N. Effect of antioxidant properties of lecithin emulsifier on oxidative stability of encapsulated bioactive compounds. Int. J. Pharm. 2013, 450, 129-137. [CrossRef] [PubMed]

44. Chen, X.; Zou, L.-Q.; Niu, J.; Liu, W.; Peng, S.-F.; Liu, C.-M. The stability, sustained release and cellular antioxidant activity of curcumin nanoliposomes. Molecules 2015, 20, 14293-14311. [CrossRef] [PubMed]

45. Lin, X.; Bai, D.; Wei, Z.; Zhang, Y.; Huang, Y.; Deng, H.; Huang, X. Curcumin attenuates oxidative stress in RAW264.7 cells by increasing the activity of antioxidant enzymes and activating the Nrf2-Keap1 pathway. PLoS ONE 2019, 14, e0216711. [CrossRef] [PubMed]

(C) 2020 by the authors. Licensee MDPI, Basel, Switzerland. This article is an open access article distributed under the terms and conditions of the Creative Commons Attribution (CC BY) license (http://creativecommons.org/licenses/by/4.0/). 